\title{
BUKU SAKU IBADAH MANASIK HAJI DAN UMROH BERBASIS ANDROID
}

\author{
Joko Dwi Santoso \\ Teknik Komputer/ Ilmu Komputer, Universitas AMIKOM Yogyakarta \\ Jl. Ring Road Utara, Condong Catur, Sleman, Yogyakarta, 55283 \\ $(0274-884201-207 ; 0274-884208)$ \\ joko@amikom.ac.id
}

\begin{abstract}
Abstrak: Haji dan Umrah adalah Muslim wajib bagi mereka yang mampu. Dalam mempersiapkan keberangkatan calon jamaah haji diberikan pengarahan yang salah salah satunya diberikan beberapa buku panduan. Ini dianggap belum praktis karena bisa memberatkan jemaat dalam beribadah. Perkembangan teknologi seperti smartphone Android dapat mengatasi ketidakpraktisan ini, sehingga dibutuhkan aplikasi mobile yang berisi panduan haji dan umrah. Dengan aplikasi ini mempermudah dan mengingatkan jamaah dalam melakukan prosesi haji dan umrah. Dalam menganalisis kebutuhan UML di antaranya adalah use case diagram, diagram aktivitas, diagram urutan dan diagram kelas. Hasil yang ingin dicapai adalah aplikasi mobile yang dapat memudahkan jamaah dan umroh dalam melaksanakan ibadah haji dan umrah. Seperti sholat dalam melaksanakan prosesi haji dan umrah. Kesimpulan dalam pembuatan skripsi ini adalah aplikasi bimbingan haji dan umrah dapat membantu dan mempermudah calon jamaah haji dan umrah melaksanakan prosesi haji dan umrah.
\end{abstract}

Kata Kunci: Mobile Application, Hajj, Umrah, UML.

Abstract: Hajj and Umrah are obligatory Muslims for those who are able. In preparing departure of prospective pilgrims given a briefing is wrong one was given several guidebooks. This is considered not yet practical because it can burden the congregation in worship. Technological developments such as Android smartphones can overcome this impracticability, so that it is needed mobile application which contains guidance on Hajj and Umrah. With this application simplify and remind the congregation in performing the Hajj and Umrah processions. In analyzing the needs of UML among them are use case diagrams, activity diagrams, sequence diagrams and class diagrams. Results to be achieved are a mobile application that can make it easier for pilgrims and Umrah in carrying out the Hajj and Umrah. Like the prayers in carrying out the procession Hajj and Umrah. The conclusion in making this thesis is the application Hajj and Umrah guidance can help and make it easier for prospective pilgrims in the Hajj and Umrah carrying out the procession of the Hajj and Umrah.

Keywords - Mobile Application, Hajj, Umrah, UML.

\section{Pendahuluan}

Ibadah haji merupakan ibadah pokok yang menjadi salah satu rukun islam kelima. Ibadah yang sangat mulia yang banyak diidamkan oleh seluruh umat islam di dunia. Tidak sedikit umat islam yang mampu melaukan ibadah mulia tersebut dan tidak sedikit pula yang mengginkan kemudahan baik dalam perjalanan maupun pelaksanaan ibadah haji itu sendiri.

Seorang muslim pasti menginginkan ibadah yang sempurna yang dinilai ibadah oleh Allah Subhanahu wa Ta'ala. Kesempurnaan itu bisa dengan niat yang ikhlas semata-mata karena Allah Subhanahu wa Ta'ala dan dengan melaksanakan rukun-rukun manasik haji dan umroh. Kesempurnaan ibadah yang ingin didapatkan seorang muslim yang menjalankan ibadah haji dan umroh ini tentunya memerlukan kesiapan berupa informasi-informasi terkat haji dan umroh beserta doa- doa pelaksanaannya. 
Jurnal Pseudocode, Volume V Nomor 2, September 2018, ISSN 2355-5920, e-ISSN 2655-1845 www.ejournal.unib.ac.id/index.php/pseudocode

Persiapan informasi-informasi beserta doa-doa tersebut akan penulis sajikan dalam aplikasi berbasis android guna memberi kemudahan bagi semua ummat muslim yang akan melaksanakan haji dan umrah.

Android bukan lagi sebuah hal yang awam dikalangan masyarakat pada era sekarang kini. smartphone yang berbasis android sudah bayak ditemukan dengan harga yang terjangkau oleh setiap orang. Penulis akan mencoba memberikan sebuah kemudahan yang menggabungkan nilai religius dengan sebuah teknologi android.

Menurut survey yang dilaukan Fadhilah pada tahun 2015 kepada 50 responden muslim berusia 25-50 tahun yang memiliki dan menggunakan android, sebanyak $60 \%$ responden masih belum memahami tentang haji. 58\% mengatakan hal tersebut disebabkan terbatasnya waktu dan $28 \%$ disebabkan oleh kurang jelasnya penjelasan yang ada pada buku panduan yang diberikan [1].

Hasil survey tersebut merupakan salah satu tinjauan dari beberapa tinjuan penulis dalam melaukan kerangka pembuatan aplikasi manasik haji dan umrah berbasis android, dengan tujuan memberikan kemudahan kepada semua pihak dalam mempelajari informasi tentang haji menggunakan bantuan teknologi media elektronik. Teknologi media elektronik yang penulis bahas adalah sebuah smartphone yang berbasis android. Berdasarkan uraian sebelumnya maka penulis akan membuat dan merancang sebuah aplikasi buku saku ibadah manasik haji dan umroh berbasis android.

Aplikasi ini merupakan aplikasi berbasis android yang di buat agar mempermudah pengguna smartphone yang ingin melakukan ibadah haji dan umroh, dimana aplikasi ini terdapat informasi-informasi dan tata cara terkait ibadah haji maupun umroh yang baik dan benar yang diharapkan memudahkan, menambah ilmu pengetahuan dan membantu para muslimin dalam pelaksanaan ibadah haji dan umroh.

\section{LANDASAN TEORI}

\section{A. Tinjauan Pustaka}

Pertama, analisis dengan judul "Aplikasi Alat Bantu Manasik Haji Berbasis Android" oleh Dian Perdana Putra tahun 2014. Pada penelitian ini, didapatkan bahwa Hasil yang didapat dari penelitian ini adalah $85 \%$ responden menyatakan aplikasi mudah digunakan, $83 \%$ aplikasi cukup lengkap, $80 \%$ aplikasi mudah dipahami, 83\% gambar cukup jelas, $85 \%$ aplikasi cukup interaktif, 93\% aplikasi cukup menarik, 82\% aplikasi membantu dalam menyampaikan atau mendapatkan informasi tentang manasik haji sehingga tujuan dari penelitian ini berhasil tercapai dengan presentase hasil yang hampir maksimal [2].

Berikutnya adalah penelitian berjudul "Aplikasi Panduan Ibadah Haji Jamaah Indonesia Berbasis Android" oleh Senjaya tahun 2012. Dalam penelitian dijelaskan bahwa aplikasi ini hadir sebagai media yang menyediakan informasi panduan, mulai dari definisi kegiatan dan Ibadah Haji, larangan Ibadah Haji dan doa untuk diketahui oleh para jamaah dalam menjalani Ibadah Haji. Melalui pengumpulan materi dan informasi, pembangunan aplikasi pemograman Android ini menggunakan IDE Eclipse, dengan bahasa markup XML dan bahasa pemograman java, juga SQLite sebagai media penyimpanan data [3].

Fadilah melakukan penelitian pada tahun 2015 berjudul "Rancang Bangun Aplikasi Pembelajaran Haji dan Umrah Berbasis Multimedia pada 
Jurnal Pseudocode, Volume V Nomor 2, September 2018, ISSN 2355-5920, e-ISSN 2655-1845 www.ejournal.unib.ac.id/index.php/pseudocode

$\begin{array}{lcll}\text { Smartphone Bersistem } & \text { Operasi } & \text { Android". } & \text { komunikasi. Sistem aplikasi mobile merupakan } \\ \text { Peneletian } & \text { ini menggunakan metode } & \text { aplikasi yang dapat digunakan walaupun pengguna } \\ \text { pengembangan sistem Rapid Application } & \text { berpindah dengan mudah dari satu tempat } \\ \text { Development (RAD) dengan tiga fase yaitu: } & \text { ketempat lain lain tanpa terjadi pemutusan atau } \\ \text { perencanaan kebutuhan, fase workshop design, dan } & \text { terputusnya komunikasi. Aplikasi ini dapat diakses } \\ \text { fase implementasi dengan perancangan proses } & \text { melalui perangkat nirkabel seperti pager, seperti }\end{array}$

UML (Unified Model Language) dan dikembangkan menggunakan android SDK, bahasa pemrograman java, HTML untuk menampilkan konten-konten aplikasi, SQlite sebagai database dan google maps untuk menampilkan peta [1].

Terakhir penelitian oleh Faisal tahun 2012 yang berjudul "Rancang Bangun Aplikasi Panduan Dan Navigasi Haji Mobile Berbasis Android" Sistem ini berisikan informasi panduan perjalanan ibadah haji yang dilengkapi dengan video, panduan doa dan dzikir yang dilengkapi dengan audio, fitur pencarian dan dilengkapi peta navigasi yang memanfaatkan fitur google map yang dapat digunakan user untuk mengetahui posisi. Setiap data tersimpan didalam handphone Android. Berdasarkan hasil kuesioner yang telah dilakukan, dari semua pertanyaan kategori sudah pernah melakukan perjalanan haji memiliki nilai diatas $84 \%$ dan diatas $74 \%$ untuk kategori belum pernah melakukan perjalanan haji menyatakan bahwa aplikasi ini membantu mereka dalam melakukan persiapan perjalanan haji [4].

\section{B. Aplikasi Mobile}

Pengertian aplikasi adalah program yang digunakan orang untuk melakukan sesuatu pada sistem komputer. Mobile dapat diartikan sebagai perpindahan yang mudah dari satu tempat ke tempat yang lain, misalnya telepon mobile berarti bahwa terminal telepon yang dapat berpindah dengan mudah dari satu tempat ke tempat lain tanpa terjadi pemutusan atau terputusnya telepon seluler dan PDA [5].

\section{Haji dan Umroh}

Secara etimologi, haji berarti menyengaja atau menuju dan mengunjungi. Adapun secara terminology Bahasa Arab, haji mempunyai arti qashd, yaitu tujuan, maksud, dan menyengaja. Menurut istilah syara', Haji ialah menuju atau mengunjungi Baitullah (Baitul Haram) dan tempattempat tertentu untuk melaksanakan amalanamalan ibadah, serta pada waktu tertentu pula. Yang dimaksud dengan temapt-tempat tertentu dalam definisi ini, selain kakbah dan Mas'a (tempat sa'i), juga Arafah, Muzdalifah, melontar jumroh, mabit di Mina. Adapun yang dimaksud dengan amalan ibadah tertentu ialah tawaf, sa'I, wakuf, mabid di Muzdalifah, meontar jumrah, mabit di Mina, dan lain-lain. Sedangkan yang dimaksud dengan waku tertentu ialah bulan-bulan haji yang dimulai dari bulan Syawal sampai sepuluh hari pertama bulan Zulhijah.

Haji merupakan rukun (tiang agama) Islam yang kelima setelah syahadat, salat, zakat dan puasa. Menunaikan ibadah haji adalah bentuk ritual tahunan yang dilaksanakan kaum muslim sedunia bagi yang "mampu", baik dari segii material, fisik, dan keilmuan, dengan berkunjung dan melaksanakan kegiatan dibeberapa temat di Arab Saudi pada waktu yang dikenal sebagai bulan/ musim haji (bulan Zulhijah). Hal ini berbeda dngan ibadah umrah yang bias dilaksanakan sewaktu-waktu [6]. 
Jurnal Pseudocode, Volume V Nomor 2, September 2018, ISSN 2355-5920, e-ISSN 2655-1845 www.ejournal.unib.ac.id/index.php/pseudocode

Umroh secara etimologi berarti berkunjung. Sedangkan secara tertimologi umroh adalah mengunjungi Baitul Haram dengan amalan tertentu Umroh merupakan salah satu kegiatan ibadah dalam agama Islam. Hampir mirip dengan ibadah Haji, ibadah ini dilaksanakan dengan cara melakukan beberapa ritual ibadah di kota suci Mekkah, khususnya di Masjidil Haram.

Pada istilah teknis syari'ah, umrah berarti melaksanakan tawaf di Kakbah dan sa'i antara Shofa dan Marwah, setelah itu memakai ihram yang diambil dari miqat, dan umrah biasa dikenal atau disebut dengan istilah "haji kecil" [7].

\section{Android}

Android adalah sebuah sistem operasi untuk perangkat mobile berbasis linux yang mencakup sistem operasi, middleware dan aplikasi. Android juga merupakan sistem operasi yang menyedikan platform terbuka bagi para pengembang untuk menciptakan aplikasi mereka sendiri [8].

\section{E. Aplikasi}

Menurut Shelly, Cashman, dan Vermant pada 2009, aplikasi adalah seperangkat intruksi dalam komputer yang dirancang agar kita menyelesaikan tugas-tugas tertentu. Sedangkan menurut Ibisa pada 2009 aplikasi adalah alat bantu untuk mempermudah dan mempercepat proses pekerjaan dan bukan merupakan beban bagi para penggunanya [9].

\section{F. UML (Unified Modeling Language)}

UML didefinisikan sebagai bahasa fisual untuk menjelaskan, memberikan spesifikasi, merancang, membuat model, dan mendokumentasi aspek-aspek dari sebuah sistem. UML dikembangkan sebagai suatu alat untuk analisa dan desain berorientasi objek oleh Grady Booch, Juim Rumbaugh, dan Ivar Jacobson [10].

\section{ANALISA DAN PERANCANGAN}

\section{A. Analisis Sistem}

Analisis sistem adalah tahap untuk mengindentifikasi sebuah masalah dan mengevaluasi masalah. Sehingga nantinya dapat di usulkan sebuah perbaikan Analisis sistem ini berguna untuk meminimalisirkan sebuah kendala dalam sebuah sistem yang akan di buat nanti dan bagian ini sangatlah penting dalam proses pembuatan dan pengembangan sistem. Analisis sistem adalah tahap untuk mengindentifikasi sebuah masalah dan mengevaluasi masalah. Sehingga nantinya dapat di usulkan sebuah perbaikan Analisis sistem ini berguna untuk meminimalisirkan sebuah kendala dalam sebuah sistem yang akan di buat nanti dan bagian ini sangatlah penting dalam proses pembuatan dan pengembangan sistem.

\section{B. Perancangan Sistem}

Perancangan sistem bertujuan untuk memberikan sebuah gambaran aplikasi yang akan dibuat agar tdak menyimpang dari hasil analisa yang telah diterapkan pada perancangan aplikasi. Analisa tersebut yang akan membuat rancanganrancangan komponen sistem ini secara rinci. Adapun rancangan sistem sebagai berikut:

i. Perancangan UML

Perancangan yang digunakan dalam aplikasi "Tuntunan Haji dan Umroh" adalah dengan UML (Unified Modeling Language). UML itu sendiri adalah bahasa yang digunakan untuk menjelaskan dan memvisualisasikan proses analisis dan design beriorientasikan objek. 
Jurnal Pseudocode, Volume V Nomor 2, September 2018, ISSN 2355-5920, e-ISSN 2655-1845 www.ejournal.unib.ac.id/index.php/pseudocode

\section{Use Case Diagram}

Use case diagram merupakan gambaran fungsionalitas dari suatu sistem yang menjeaskan interaksi antara aktor dengan sistem. Dan berikut use case diagram yang menjelaskan antara aktor dengan sistem pada Gambar 1 berikut ini:

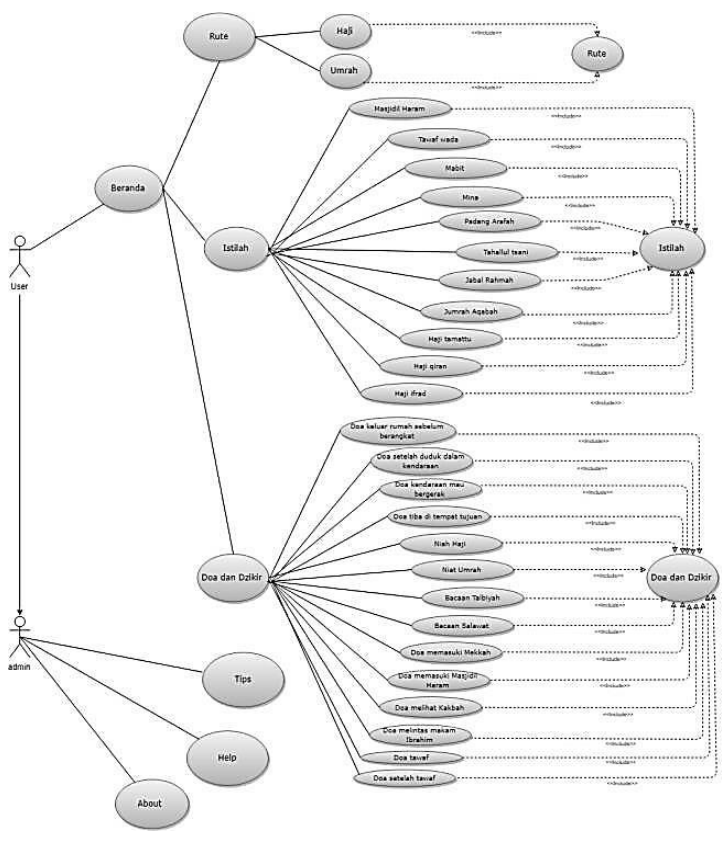

Gambar 1. Use Case Diagram

\section{Activity Diagram}

Activity Diagram merupakan gambaran alur aktivitas dari sebuah sistem yang sedang dirancang. Menjelaskan alur dari awal mulai use berinteraksi dengan sistem sampai selesai.

\section{Class Diagram}

Class diagram adalah suatu pemodelan suatu sistem untuk memvisualisasikan struktur dan memperlihatkan hubungan antar kelas dari suatu sistem. Berikut class diagram pada Gambar 2 dari aplikasi ini:

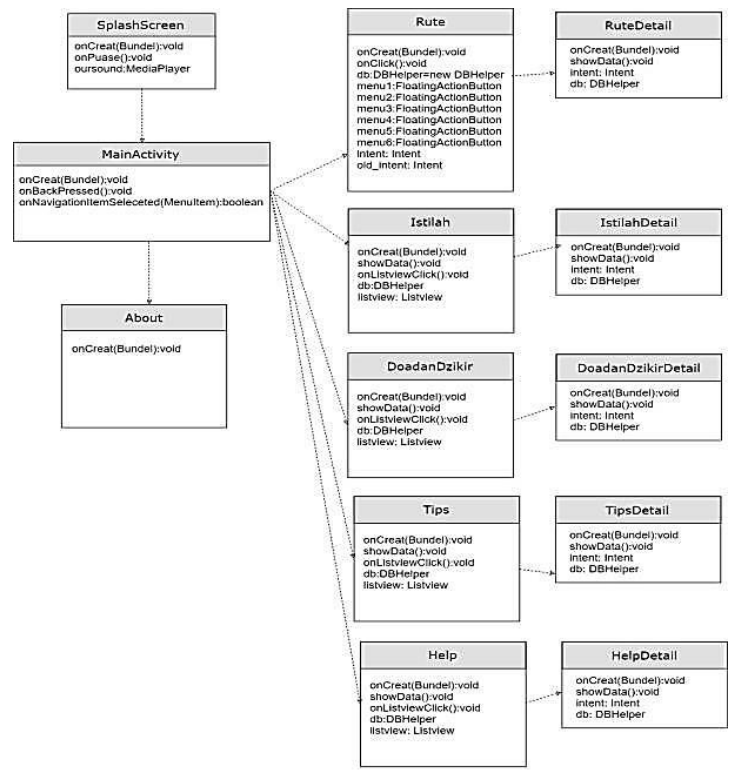

Gambar 2. Class Diagram

\section{Sequence Diagram}

Sequence diagram adalah langkah langkah yang menjelaskan proses respon dari event antara objek dan sekitar sistem berupa massage yang digambarkan terhadap waktu. Terdiri dari dimensi vertical (waktu) dan dimensi horizontal (objek terkait). Berikut sequence diagram pada Gambar 3 dari aplikasi ini:

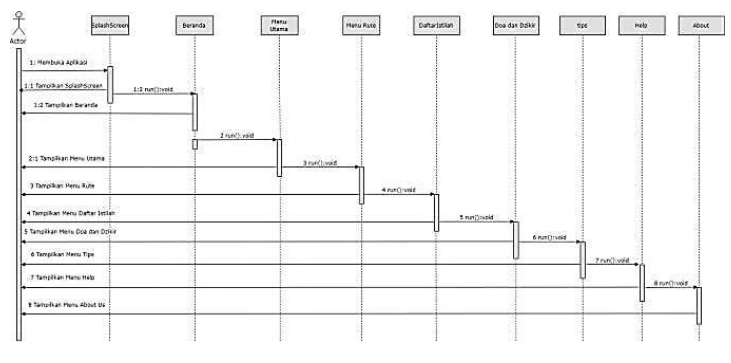

Gambar 3. Sequence Diagram

\section{ii. Perancangan AntarMuka}

Perancangan antarmuka merupakan bagian penting dalam pembuatan apliksi, karena proses ini memberi gambaran bentuk aplikasi yang dibuat. Sehingga akan terlihat jelas kemudahan dalam menggunakan aplikasi ini. 
Jurnal Pseudocode, Volume V Nomor 2, September 2018, ISSN 2355-5920, e-ISSN 2655-1845 www.ejournal.unib.ac.id/index.php/pseudocode

1. Tampilan Splashscreen

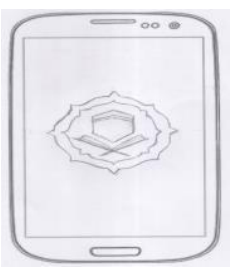

Gambar 4. Tampilan splashscreen

2. Tampilan Beranda

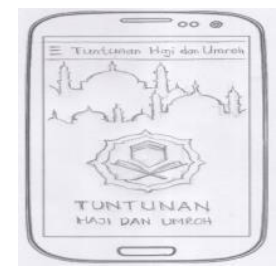

Gambar 5. Tampilan Beranda

3. Tampilan Menu Utama

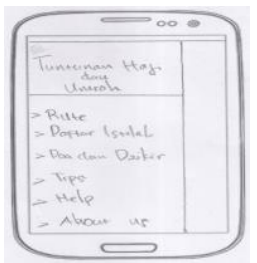

Gambar 6. Tampilan Menu Utama

4. Tampilan Menu Rute

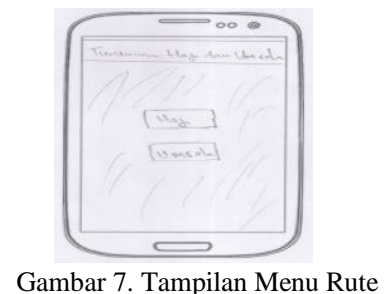

5. Tampilan Menu Daftar Istilah

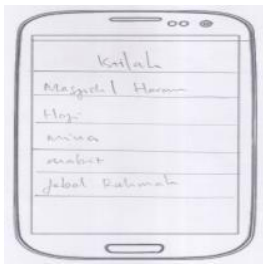

Gambar 8. Tampilan Menu Daftar Istilah
6. Tampilan Menu Doa dan Dzikir

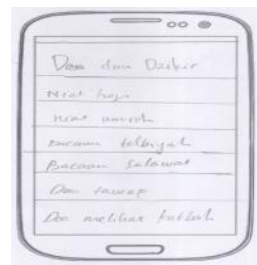

Gambar 9. Tampilan Menu Doa dan Dzikir

7. Tampilan Menu Tips

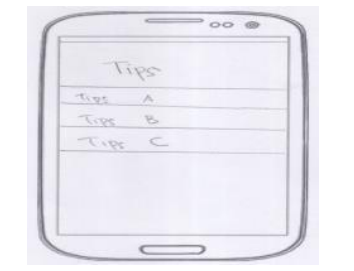

Gambar 10. Tampilan Menu Tips

8. Tampilan Menu Help

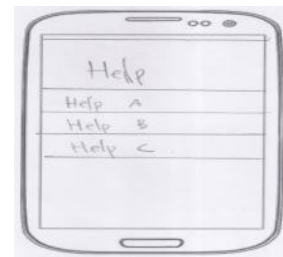

Gambar 11. Tampilan Menu Help

9. Tampilan Menu About Us

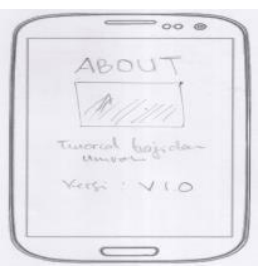

Gambar 12. Tampilan Menu About Us

\section{IMPLEMENTASI DAN PEMBAHASAN}

\section{A. Implementasi}

Tahapan selanjutnya adalah Implementasi yaitu tahapan untuk mengoprasikan atau menjalankan aplikasi yang sudah melewati tahap analisis dan perancangan pada bab sebelumnya untuk diimplementasikan sehingga menghasilkan aplikasi yang diinginkan dan sesuai dengan fungsi dan tujuan dibuatnya apliksi ini. 
Jurnal Pseudocode, Volume V Nomor 2, September 2018, ISSN 2355-5920, e-ISSN 2655-1845 www.ejournal.unib.ac.id/index.php/pseudocode

\section{B. Pengujian Aplikasi}

Pengujian adalah tahap yang dilakukan untuk menguji aplikasi yang telah dibuat dan telah diimplementasikan sedemikian rupa sesuai dengan fungsinya. Metode pengujian yang digunakan adalah metode black box untuk memberikan gambaran apakah sistem atau aplikasi yang dibuat dijalankan sesuai dengan fungsional sistem atau aplikasi tersebut.

Pada tahapan ini, testing dilakukan oleh pembuat aplikasi apakah sesuai dengan yang diharapkan apa tidak dan apakah berjalan lancar apa tidak. Uji coba menggunakan smartphone berjenis Meizu m2 Note dengan hasil pada Tabel 1 berikut ini.

Tabel 1. Hasil Pengujian Beta Test

\begin{tabular}{|c|c|c|c|c|c|}
\hline No & Pernyataan & SS & $\mathrm{S}$ & $\mathrm{KS}$ & SKS \\
\hline 1 & $\begin{array}{l}\text { Aplikasi berhasil } \\
\text { diinstal dan berjalan } \\
\text { baik di perangkat } \\
\text { mobile anda. }\end{array}$ & 9 & 11 & & \\
\hline 2 & $\begin{array}{l}\text { Tampilan aplikasi } \\
\text { menarik dan sangat } \\
\text { mudah di pahami. }\end{array}$ & 1 & 18 & 1 & \\
\hline 3 & $\begin{array}{l}\text { Ketersediaan daftar } \\
\text { menu yang } \\
\text { menyediakan informasi. }\end{array}$ & & 19 & 1 & \\
\hline 4 & $\begin{array}{l}\text { Informasi yang } \\
\text { ditampilkan sesuai } \\
\text { dengan perjalanan haji } \\
\text { dan umroh. }\end{array}$ & 9 & 9 & 2 & \\
\hline 5 & $\begin{array}{l}\text { Foto, warna dan tombol } \\
\text { pada aplikasi sudah } \\
\text { sesuai. }\end{array}$ & & 19 & 1 & \\
\hline & Total & 19 & 76 & 5 & \\
\hline
\end{tabular}

Keterangan pilihan:

$$
\begin{aligned}
& \text { SS : Sangat Setuju } \\
& \text { S : Setuju } \\
& \text { KS : Kurang Setuju } \\
& \text { SKS : Sangat Kurang Setuju }
\end{aligned}
$$

Jumlah responden sebanyak 20 orang. Dengan jumlah pernyataan sebanyak 5 pernyataan, maka total skor adalah 100. Dari tabel kuisioner diatas jumlah skor yang setuju adalah 76, dan sangat setuju sebanyak 19, kurang setuju 5 dan sangat kurang setuju sebanyak 0 , maka didapat persentase sebagai berikut:

SS (Sangat Setuju): $19 / 100 \times 100 \%=33.3 \%$

S (Setuju): $76 / 100 \times 100 \%=66.7 \%$

KS (Kurang Setuju): 5/100 x 100\% =0\%

SKS (Sangat Kurang Setuju): 0/100 x 100\% =0\%

Dari hasil di atas didapat sebanyak 19\% sangat setuju, $76 \%$ setuju, $5 \%$ kurang setuju dan $0 \%$ sangat kurang setuju. Maka dapat disimpulkan bahwa aplikasi Tuntunan Haji dan Umroh sudah sesuai dengan tujuan yaitu sebagai informasi tentang tata cara manasik haji dan umroh dimana nantinya semua jamaah haji maupun umroh bisa memahami, sehingga dalam perjalanan tidak mendapatkan kesulitan.

\section{Spesifikasi Pengguna}

Spesifikasi dalam penggunaan aplikasi "Tuntunan Haji dan Umroh" ini tidak membutuhkan spesifikasi yang tinggi. Spesifikasi hardware minimal menggunakan spesifikasi sebagai berikut yang terdapat pada Tabel 2 .

Tabel 2. Spesifikasi Hardware

\begin{tabular}{|l|l|}
\hline Layar & Ukuran: 4.0 inch, 480 x 800 pixels \\
\hline Memory & $512 \mathrm{MB}$ \\
\hline Battery & Standard battery, Li-Ion $1350 \mathrm{mAh}$ \\
\hline OS & Android OS, 4.1.1 (Jelly Bean) - OS, \\
& 7.0 (Nougat) \\
\hline CPU & $1 \mathrm{GHz}$ \\
\hline
\end{tabular}

\section{Publikasi}

Setelah melakukan uji coba dengan beberapa responden, dan menyesuaikan dengan umpan balik yang diberikan. Akhirnya aplikasi Tuntunan Haji dan Umroh berhasil dirilis di Play 
Jurnal Pseudocode, Volume V Nomor 2, September 2018, ISSN 2355-5920, e-ISSN 2655-1845 www.ejournal.unib.ac.id/index.php/pseudocode

Store dengan harapan banyak orang yang bisa memahami perjalanan haji maupun umroh sebelum melakuakan ibadah. Berikut ini beberapa bukti publikasi aplikasi Tuntunan Haji dan Umroh yang telah dirilis di Play Store:

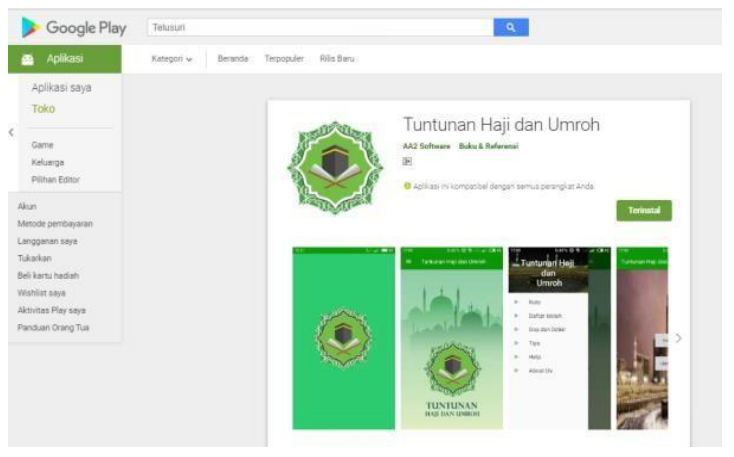

\section{KESIMPULAN}

Berdasarkan penjelasan dan pembahasan yang telah diuraikan pada bab sebelumnya hingga tahap implementasi, maka bisa diambil kesimpulan sebagai berikut:

1. Aplikasi ini dapat menampilkan daftar istilah, doa dan dzikir, tips beserta penjelasan mengenai perjalanan haji dan umroh. Aplikasi ini diharapkan dapat menjadi refrensi bagi masyarakat yang akan melaksanakan ibadah haji dan umroh.

2. Penjelasan yang ada di aplikasi ini mudah dimengerti oleh user.
3. Aplikasi Tuntunan Haji dan Umroh berbasis android ini dibangun melalui proses planning, analisis design, coding dan testing.

\section{REFERENSI}

[1] A.F.Albani, "Rancangan Bangunan Aplikasi Pembelajaran Haji dan Umroh Berbasis Multimedia pada Smartphone Bersistem Oprasi Android". Universitas Islam Negeri Syarif Hidayatullah. 2015.

[2] D.P.Putra, A.Rakhmadi, D.A.Prasetya, "Aplikasi Alat Bantu Manasik Haji Berbasis Android". Universitas Muhammadiyah Surakarta. 2014.

[3] S.F.Senjaya, "Aplikasi Panduan Ibadah Haji Jamaah Indonesia Berbasis Android". Universitas Telkom Bandung. 2012.

[4] A.Faisal, "Rancang Bangun Aplikasi Panduan dan Navigasi Haji Mobile Berbasis Android”. Politeknik Caltex Riau. 2012.

[5] S.S.Hermawan, Mudah Membuat Aplikasi Android. Yogyakarta: Andi 2011.

[6] M.S.Al-Utsaimin, Manasik Haji \& Umrah \& Beberapa Kesalahan Yang Dilakukan Sebagian Jama'ah, Surakarta : Biro Perjalanan Hajidan Umrah Asslaaam. 2006.

[7] Y.Supardi, Semua Bisa Menjadi Programmer. Android Case Study, Sejarah Android. Jakarta : PT. Elex Media Komputindo. 2014.

[8] N.H.Safaat, Android Pemrograman Aplikasi Mobile Smartphone dan Tablet PC Berbasis Android. Bandung: Informatika. 2011.

[9] Munawar, Analisis Perancangan Sistem Berorientasi Objek dengan UML. Bandung : Informatika. 2018. 